\title{
The Task for Leadership: Sustaining Research Excellence in Uncertain Times
}

\author{
James Moeser
}

Chancellor Emeritus, University of North Carolina at Chapel Hill

$\mathrm{I}$ was delighted to receive the invitation to speak at this, the $14^{\text {th }}$ annual research retreat sponsored by the Merrill Center for Advanced Studies at KU. I was privileged to attend and speak to the very first of these retreats in 1997, attending as the relatively new chancellor of the University of Nebraska-Lincoln. At that conference, my task was to be the clean-up hitter, listening to the presentations of faculty from the several institutions, summing up what I heard, and adding my own reflections in a piece I called “The Agenda for Change."

My task this time as the lead-off hitter is much more daunting, without the benefit of the shared wisdom of those of you in this room to draw on. It is our good fortune that I am followed in the line-up by two great hitters, Harvey Perlman and Bernadette Gray-Little, and I am confident of their ability to knock me in, provided I can get on base.

My charge from Mabel Rice is to articulate how top leaders can sustain research excellence for a public university in a time of fluctuating and uncertain public and financial support. She suggested that I might provide a list of the ten most useful things I learned about leading a research university, drawing most heavily from my eight years as chancellor of UNC Chapel Hill. In this paper, I will develop ten general principles, which I hope you will find helpful.
The perspective from the top ... That reminds me of a story:

A man in a hot-air balloon realized that he was lost. He reduced altitude and spotted a woman below. "Excuse me," he shouted. "Can you help? I promised a friend I would meet him an hour ago, but I don't know where I am."

The woman looked up and replied: "You are in a hot-air balloon hovering approximately 30 feet above the ground. You are between 40 and 41 degrees north latitude and between 59 and 60 degrees west longitude."

"You must be an engineer," said the balloonist.

"I am," replied the woman. "How did you know?"

"Well," said the balloonist, "everything you told me is technically correct, but I have no idea what to make of your information and the fact is, I am still lost. Frankly, you've not been much help so far." 
"Well," said the woman, "you must be an administrator."

"I am," said the balloonist. "How did you know?"

"Well," said the woman, "you don't know where you are or where you are going. You have risen to where you are due to a large quantity of hot air. You made a promise that you have no idea how to keep. And you expect people beneath you to solve your problems. The fact is that you are in exactly the same place you were before we met - but, now, somehow, it's my fault."

Notwithstanding the cynicism of that little story, I believe that top leadership can impact the direction of a university; it can help create a climate that supports excellence in research; indeed, it can create a culture of excellence in an institution.

A savvy leader, unlike the balloonist, knows where he or she is not just the geographical coordinates, but more critically, the history and culture of the institution, the state, and the region. Large universities turn like battle ships. Course corrections are possible, but only gradually, by increments.

We must always remember that a research university is a complex organization with a diffuse power structure. Presidents and chancellors lead by persuasion, not by fiat. Indeed, the more successful an institution is in attracting external funding, whether from peer-reviewed grants, foundations, or donors, the more decentralized the institution becomes. A highly successful faculty member can control more resources than many deans or department chairs.
As I began to think about these remarks, it occurred to me that I should review what I said back in 1997. Indeed, the first two principles I will give you this morning come from that earlier paper.

Paul Cheney, a distinguished KU neurophysiologist, made a compelling argument for lowering the walls that divide the many silos inside the academy. He quoted Mark Rogers, then the Vice Chancellor for Health Affairs at Duke, who wrote the following:

"The institutions that will succeed [in the future] are those that can reorganize themselves to address scientific and educational questions in an interdisciplinary manner. The institutions that will have difficulty are the ones that keep the same rigid structure that prevents pollination among disciplines."

That concept became a mantra for me at Nebraska and later at North Carolina. The more I realized the futility of attempting to dismantle hardened walls, the more I began to use the language of biology to speak of walls that were more like permeable membranes.

However one characterizes it, this is an essential culture for a successful research university.

Eli Michaelis, the chair of KU's pharmacology and toxicology department, spoke eloquently about the two factors that drive successful researchers -uncertainty and urgency. He also spoke candidly and revealingly about his own fear of failure, observing that the most audacious objectives carried with them the greatest risk of failure. I distilled a principle out of this that I applied to my own objectives for two universities: The greater the attempt, 
the greater the reward, and also the greater the risk of failure. It is this sobering realization, however, that often leads to the ultimate failure of leadership - the failure to act. Institutions that coast are, by definition, on a down-hill track.

I arrived in Chapel Hill in August of 2000 at a precipitous moment in the history of this, the oldest public university in America. The campus was showing its age. After years of neglect from the state, deferred maintenance was at an alarming stage. Our worldclass chemistry department was still teaching and doing research in a 1925 building. The music library, one of the three strongest research collections in America, was housed in a basement of an old Carnegie Library with leaking pipes running overhead. I was replacing a chancellor who had died in office, leaving a substantial structural budgetary deficit. I had to find a provost, a chief financial officer, and a chief research officer.

To counterbalance these problems (which I saw as opportunities) were many positives. First, I discovered an incredibly positive faculty culture. Unlike my experience at three other universities, where the best faculty had opted out of governance, some of UNC's most distinguished faculty were highly active in governance and eager to work with a new chancellor. It was not uncommon for the faculty chair to be a member of one of the national academies. UNC was recognized in the then-just released Lombardi ranking of research universities as one of only four public research universities in the top tier along with Berkeley, Michigan, and UCLA.
I quickly realized that the strategies I had employed at Nebraska, and earlier as provost at South Carolina, with significant reallocation of funds from marginal areas to concentrated and focused areas of excellence, would be inappropriate for a university with very few areas that could be called weak, and many that were excellent and highly regarded. I adopted a strategy that we would have a low tolerance for marginal programs, which meant, with a small number of such programs, we could afford to move resources to shore them up.

(If there is a principle that can be distilled here, I believe it is this:

In developing institutional strategic objectives, one must always begin with an honest institutional assessment. I strongly believe in setting high goals, but those goals need to be grounded in reality).

On the November, 2000 ballot was a \$3.2 Billion higher education construction bond issue, of which $\$ 525$ Million was slated to go to Chapel Hill. In my installation address in October, I took a deep breath and pledged to the voters that we would triple that investment in private fund raising if they would approve the bonds. (We were on the cusp of announcing a billion dollar-plus capital campaign, but I had great anxiety about our ability to raise that kind of money. This is an example of my earlier point about the fear of failure.)

Timing is everything - in hand grenades, music, and politics. In November of 2000, the dot-com bust was still over the horizon. People were optimistic. The voters approved the 
bond issue with a 75\% plurality, passing in all 100 counties. It stands, still to this day, as the largest higher education construction bond ever passed by any state. Fortunately, because of the success of the Carolina First Campaign, which ultimately raised $\$ 2.4$ Billion for academic support including 225 endowed chairs, nearly a thousand new scholarships and fellowships, and significant commitments to facilities for research, I was able to relax. At the end of the day, we had increased the state's investment five-fold.

I realized that this was a critical moment in the history of this university. UNC was highly ranked, but also highly vulnerable, due to these obvious deficiencies in the infrastructure and relatively low faculty salaries. Instinctively, I felt that this was the right time for a major investment in big science. We had obvious strengths on which to build, and I knew that it would be a fatal mistake to begin my first big efforts in my own playground of the arts and humanities. I also realized that I needed really a strong internal leadership team to develop a strategy. With my lack of background in science, I needed senior colleagues with strong research credentials. So, I recruited Robert Shelton, the vice president for research of the University of California, a physicist and former department chair at UC-Davis, to be provost. We recruited Tony Waldrop, the vice chancellor for research at Illinois, to take the same position at UNC. (When Shelton left after several years to become president of the University of Arizona, I named Bernadette Gray-Little, the dean of the College and now KU's chancellor, to be our provost.) I always had a strong colleague in that essential office.

We decided that the capital construction program, which over eight years grew to $\$ 2.2$ Billion and more than 6 Million new square feet, would be front-end loaded with research and teaching facilities for the physical sciences, medicine, public health, and pharmacy. We drafted our leading research faculty into planning teams for these new buildings. (The ability to dream and then build new facilities is one of the strongest retention devices I know.) We also used these new facilities, even in the planning stages, as the hooks for recruiting new faculty. Every area of the university was affected by this infusion of support, but none more than the physical science departments of the College - chemistry, physics and astronomy, marine science, biology, and computer science.

Early on, in my very first year, when we were fortunate enough to receive a huge bolus of new faculty lines due to enrollment growth, we made the critical decision to hold back 18 lines for a new investment in genomics to create the Carolina Center for Genome Sciences, with faculty appointments from seven different academic units representing over 15 departments and disciplines. To chair a new department of genetics in the School of Medicine, we recruited Terry Magnuson from Case Western Reserve University. He brought with him his 15-member research group, and 10,000 mice. Magnuson is a preeminent geneticist who could have gone anywhere but chose Carolina because he was attracted by the idea of creating a really big center. Candidly, another part 
of the attraction was the fact that we promised him a building. Ultimately, we built two massive research buildings, with still two more on the way. Terry now helps us recruit new faculty telling them, "these people make promises, and they deliver. They keep their word."

What are the lessons from this experience that I can pass on to you as principles? First, physical facilities matter. We are, indeed, in an arms race of facilities, and the best faculty will migrate to the places that provide them the tools to do their best work. That means state-of-the art equipment. But it also means flexible space that is well designed to maximize human interaction. We designed our buildings with connecting bridges and with meeting spaces and break-out rooms along the corridors and even in the bridges to encourage and facilitate the occasional "ah-ha" moments that sometimes lead to creative breakthroughs. Our goal was that this science complex (which is still under construction ten years later) would allow one to walk through all the science departments in the College to the health science schools in one continuum.)

The corollary principle, one that I articulated in 1997, is: faculty have to be recruited in clusters, not one at a time. The really big questions cross all the traditional boundaries. This means that departments can no longer exercise complete autonomy over hiring. I don't mean to suggest a totally top-down process for hiring decisions, but rather a negotiated process involving the provost and the top leadership.

To pursue such a strategy requires a plan, an architecture for strategic investment. Once I had the leadership team in place, I charged the provost with the development of an academic plan, which we adopted in July, 2003. A good plan needs to be specific enough to include concrete action steps, assignment of responsibility and a mechanism for measuring success. It also needs to be flexible enough to allow for opportunistic adjustments as the environment evolves.

\section{Building Public Support}

As I think back about my eight years in the chancellor's office, I am struck by how much of my time and effort was devoted to building public support for the university's research mission. We learned much from the successful campaign in the fall of 2000 to pass the higher education construction bond. We learned that there was a large reservoir of support for the university among the people of North Carolina. They loved us, but they knew very little about what we do or how we contribute to the betterment of their existence, other than the education of their sons and daughters. That told us we had some major work to do in telling our story.

That also translated into problems we had in the state legislature. For years, the state and/or the university system had been reducing our state appropriation by a percentage (up to $25 \%$ ) of our federal F\&A receipts, with the mistaken view that the campus was adequately compensated for its conduct of research, and these state funds constituted "double dipping." (This, of course, reflects a total misunderstanding of the inadequacy of the federal F\&A rate, which needs no discussion here.) 
I helped our Board of Trustees understand how critical reversing this practice was to moving forward the university's research agenda. We had an urgent case in the construction of the science complex, where a portion of the first phase was going to be shelled-in without additional resources. (The state had included a private fund-raising component for every one of our projects that received the total $\$ 525$ million in bond funds.) We needed to build out the shelled space in order to retain a key faculty member who was being heavily recruited by several other universities, but we had not yet raised the private funds. We devised a plan to finish the space by using F\&A funds to back-stop future private fund-raising. But that plan would fail, if the state, in effect, took part of our F\&A away.

Our board mobilized and formed a political action committee, which in a short period of time became one of the most powerful political lobbies in North Carolina, the second largest political action group in the state. The PAC's existence and effectiveness were not always appreciated by the system administration and board, and it was regularly attacked in the editorial pages of the local press as it grew more and more powerful.

The PAC quickly made a legislator's position on F\&A retention as the proxy for being a friend of Chapel Hill and thus meriting the PAC's support. Gradually, the climate on our retention of $\mathrm{F} \& \mathrm{~A}$ receipts began to change. I recall the first time I had to testify before a legislative committee, facing open skepticism about our plans for using
F\&A receipts to leverage research growth.

I decided to try to disarm them with a little self-deprecating humor saying, "Proteomics, Genomics, . . . all these "omics." What do I know about them? I'm only a humble village organist." This seemed to work. They smiled and relaxed and began to listen. The point I really wanted to make is that we intended to use F\&A receipts, including anticipated receipts on future research, as front-end cash to build out our research facilities, to back-stop anticipated private fund-raising.

Fortunately, over time, we began to win those arguments. While I would like to think it was the force and logic of our argument that won the day, I cannot discount the political power of the PAC. However, it was not all brute political force. Gradually, we began to succeed in connecting research to economic development, a powerful argument for state support. We marshaled the support of the major private sector researchbased firms in Research Triangle Park, many of which had their origins in university-based research. The CEOs of these firms contributed directly to the PAC and they spoke up for us in the legislature.

Gradually, we turned the tide on F\&A receipts, and in a couple of years there were no more recorded votes on UNC's F\&A receipts. We were free of any state or system control with regard to their usage, allowing us to use F\&A funds to finish space in the new science complex that would have otherwise been shelled-in, creating research space that enabled us to win a fierce battle to retain a key scientist. With this 
dedicated space and about ten new faculty lines, we established a new Institute for Advanced Materials, Nanoscience, and Technology. I recall that the year we did this, 2002, was a particularly difficult year, in which we were facing budget cuts, and I took some political risk in making such a bold move in an otherwise down year. In my State of the University address in September, I said this:

Some will argue that we cannot afford new initiatives in the current environment. I would respond that, while we must be very judicious in taking on new projects, we cannot afford not to build on our strengths to be the very best that we can be. I think we should all agree on one thing - that we will start nothing that we are not willing to support sufficiently to make it a top-10 program within a reasonable period of time. We must be willing to pull the plug of life support on new programs that fail to meet that threshold. ${ }^{2}$

This was an investment that paid off. Within five years, UNC was in the top ten nationally based on NSF funding in this area, competing with universities all of which had big engineering schools.

Between 2000 and 2009, UNC plowed \$43 Million in F\&A funds directly into research facilities, and another $\$ 90$ Million into debt service on research construction with an asset valuation of \$236 Million.

What began as a defensive strategy to protect our F\&A receipts gradually evolved into a continuing program of advocacy for the university and its research enterprise. By the end of my tenure, we were coming to the end of the funding stream from the Higher Education Construction Bond, and yet our needs and aspirations had expanded. Also, by this time, we had established strong relationships with the political leadership in the North Carolina Senate, who had become strong supporters, some would say patrons, of UNC's research enterprise. In fairly rapid succession, the North Carolina legislature funded a new UNC Cancer Hospital (\$180 M), a new research building for the School of Dentistry, and a bio-medical imaging building (\$350 $\mathrm{M})$, the last in a year when there was no other capital construction funding anywhere else in the state. However, the most stunning demonstration of the legislature's support for UNC research was the appropriation in 2008 of $\$ 50$ Million in continuing funding for cancer research. UNC is effectively leveraging that funding stream to increase its funding from federal sources.

The point to be made here is the importance of building public and political support in our respective states for the research enterprise of a public research university. We should capitalize on our status as flagship institutions and make the case to state policy makers that we are the principal drivers of innovation that leads to economic development and job creation. This case is easier to make today than it was ten years ago. We should never apologize for being research universities; we should never apologize for research, but rather celebrate it and find ways to connect our research to people's lives.

One of the clearest paths of connection to people's lives is through our educational outreach programs. At UNC, the Morehead Planetarium and 
Science Center has long been the center of our outreach for children and youth. One out of three North Carolinians under the age of 18 has visited the Morehead on campus. Thousands more have benefited from the "science bus" that takes hands-on science experiences to North Carolina high schools. Next fall, the Morehead will sponsor a twoweek state-wide science festival, with over 400 events in 100 plus locations across North Carolina. Our goal is to put the spotlight on science, to do for science in the $21^{\text {st }}$ century what state fairs did for agriculture in the $20^{\text {th }}$. We believe that this is a model that can be adopted by other states, and we are inviting people from other states to come as observers. While this is not designed as a public relations tool, we believe this festival can have a powerful effect in building public support for what we do.

The North Carolina story is one that can be replicated in other states. Strong state support can leverage strong federal support and strong private support, and vice versa. Each of these is mutually reinforcing of the others.

Public Support for Faculty Salaries

If there was a single thread that ran through all of my public presentations during my tenure, it was the importance of faculty salaries. We made faculty support the number one priority of the Carolina First Campaign, creating 225 endowed professorships. It was also the centerpiece of our legislative efforts as well.

I convinced the Board of Trustees of the importance of recruiting and retaining the best faculty as the centerpiece of all we were attempting to do. They got it. The PAC got it, and they were enormously helpful. Once we won the F\&A battle, faculty salaries became the issue.

I won't belabor this issue, because you all understand the importance of faculty support to furthering the research agenda. The point I want to make here is that this is an argument that you have to win with the public and with policy makers.

We fought this battle on three fronts - in the legislature, for state appropriations; with the system over the right to raise tuition when the state was unable to provide salary increases; and as the centerpiece of the fund-raising effort.

I used to say that we wanted to have a faculty that the University of Chicago wanted. The trouble is that the University of Chicago (and their several peers) came calling. In 2003, we discovered that we were losing two out of three contested counter-offers. This was a clear path to mediocrity. It was a crisis. We were at a difficult time in terms of state support, with several years of little or no increases in faculty compensation.

North Carolina has a long tradition of low tuition coupled with generous state support. When that support went into decline, however, it was critical that we turn to tuition as a funding source for faculty salaries. We succeeded in getting authorization from the legislature to increase tuition and to keep those funds on campus for faculty support and need-based student aid. Simultaneously, we created the Carolina Covenant program, which guaranteed all students at or below $200 \%$ of the 
federal poverty level, a debt-free graduation. This program became a national model.

Even with these safeguards in place, I still had major battles with the system Board of Governors, which had little sympathy for the plight of its flagship research campus and no understanding of the competitive environment for research universities. Once again, the PAC came to our rescue, convincing the legislature to overrule the system board. Perhaps my most telling argument to them was the fact that UNC faculty across the university averaged $\$ 211,000$ in external funding, while the average salary was about $\$ 165,000$. Talk about a return on investment, this was it!

Three years later, as a result of salary increases funded largely from tuition sources, we had reversed the negative trend, winning two out of every three contested retentions. By the time I left office, after two very good years of state appropriations, UNC's faculty salaries, by rank, were higher than either Michigan or Virginia, and only slightly behind UC Berkeley and UCLA, our four major national peers. This was a key part of our overall strategy, and I am convinced our success with regard to faculty compensation was directly related to the success of our research effort. The run-up in research funding at UNC is an impressive story. External research at UNC increased from $\$ 375$ Million in 2000 to $\$ 716$ Million in 2009, and as of June 30, 2010, has just crossed the $\$ 800$ Million threshold.

\section{Vision}

In 2003, when the NIH Roadmap initiative was first announced, we commissioned a team of our best scientists, some of whom had just been recruited in the early wave of faculty appointments, to plan for the Roadmap, which itself, would map the future of $\mathrm{NIH}$ initiatives. As a result of this initiative, UNC led the nation with the number of Roadmap awards in the first year and again in the second.

We were totally opportunistic in this case. We were fortunate that our strengths mapped well with where we thought the NIH wanted to go, and we put major resources into place in order to be competitive.

Given the investment the state was also making in research infrastructure and, later, direct research support, we could leverage each of these elements constructively.

Here, perhaps, I can derive another principle. To be successful in big science, institutions need to think strategically, placing bets by allocating resources where there may be a big return. This requires a certain degree of central planning, just as we did with the $\mathrm{NIH}$ roadmap. To be sure, a successful university will always have a balance of individual PI grants and some big teambased grants. But the major leagues are dominated by the latter, not the former. This requires us to be brutally honest about our capabilities. There are some big opportunities out there that we simply do not have the resources to address. No amount of incremental funding would matter. We have to be willing to say no to investment in such ideas, attractive as they may be to one or more advocates. This is a critical point. Great universities do not dabble in areas where they lack strength or competence. It is important to know when to say no, to have 
the courage to say it, and to stick with your decision.

In 2006, in my fall State of the University address, I hit the campus with a blockbuster. With external funding at just short of $\$ 600$ Million, I proposed establishing a goal of $\$ 1$ billion in external funding by 2015. I arrived at this number in close consultation with Tony Waldrop, the vice chancellor for research, who assured me that, while this was a huge stretch goal, it was not impossible. This is what I said:

Let us be crystal clear about this: $\$ 1$ billion is a stretch goal, more than $\$ 200$ million above what we might be expected to reach at our current trajectory. Some have argued that this is too high ... unrealistic ... that the uncompensated cost of this research will be unaffordable. To use a Jim Collins term, this is a "big, hairy, audacious goal," appropriate for a university aspiring to be the leading public university. We should dream no small dreams. ${ }^{3}$

Sometimes it is important for a leader to lay out something like this, without the assurance of success, remembering that big goals carry with them the high risk of failure. Just as I did not have absolute confidence in my promise in 2000 that we would triple the people's investment in the bond issue, and I am not certain that UNC will reach this goal. But I am certain that it is on a positive trajectory to do exactly that, and, in my opinion, that is all that matters.

I believe that this is one of the major responsibilities of leadership to set a vision, and to be the principal cheer-leader for that vision.

Over time, I discovered that one of the things state policy makers could quickly grasp was the connection between research, tech transfer, and job creation. When I arrived in Chapel Hill, UNC had a dismal record of creating spin-offs; the tech transfer office was seen as a barrier, rather than a bridge; the institutional culture was anything but supportive of entrepreneurship. We worked hard to change that culture.

My partner in this effort was Tony Waldrop, the vice chancellor for research, whose title we changed to research and economic development. We beefed up the tech transfer office, brought in new leadership, and we listened to our most entrepreneurial faculty about what they wanted and needed. I made a key change in the Office of General Counsel, another office that was seen as a major obstacle.

Over time, we saw a complete transformation of the culture for tech transfer from negative to positive. In 2004 UNC received one of seven grants in a national competition from the Ewing M. Kauffman Foundation to embed entrepreneurship into the curriculum. By placing this new program as an undergraduate minor in the College, not in the Business School, we were able to impact the entire campus. As a result, today we have programs in social entrepreneurship, and artistic entrepreneurship, not just the usual suspects from science, technology, and the health professions. The culture really did change.

However, as I left office in 2008, I could still occasionally hear complaints from our faculty about the pace of tech transfer. We still were not where we needed to be for our most ambitious faculty entrepreneurs. In December, 
2009, Tony Waldrop and his colleagues announced a real breakthrough, that Cathy Innes, UNC's director of the Office of Technology Development, called, "the Holy Grail in technology transfer transactions - the standard license agreement." ${ }^{4}$ The Carolina Express License ${ }^{5}$ offers the same terms to all UNC start-ups and offers the best deal available from the University, covering a widely divergent stream of deal-flow with minimal negotiation. I can't claim any credit for this development, which occurred after I left office, except to say that it all started with a fundamental policy shift to be an entrepreneurial university. In my opinion, this is where research universities need to be, especially public universities. That is at least a part of our reason for being as servants of society.

This focus on economic development and job creation needs to be kept in focus and in balance. It is a hand that can easily be overplayed, and this is a trap that must be avoided. It cannot become the only metric for success. There is a second trap here that is especially tempting for trustees, and that is to make the funding stream from licensing fees the goal. Everybody wants the next Gatorade. The new Carolina Express License actually makes concessions on this point, sacrificing some short-term financial return in favor of more rapid spin-off creation.

Finally, I must speak about the arts and humanities. I am personally sensitive to this area, because it is my own. I was acutely aware that in my first five years at UNC, much of my time and energy was spent on big science, medicine, and technology. These were areas of critical concern and major opportunity.

However, I was also aware of the fact that I presided over a university with a distinguished history in the arts, humanities, and social sciences. In fact, one of Carolina's strengths was the balance among each of these major areas. I regarded that history as a treasure that I was determined to preserve and protect.

One of the early decisions that Provost Shelton and I made together when the budget cuts began early in the decade was that, at all costs, we were going to protect the library. Not the serials budget, but the acquisitions and operations budget of the library.

As time passed and our position became more and more secure, we turned gradually to providing more direct support to the arts and humanities. We made a major investment in the performing arts presenting program, for example. We made sure that some F\&A resources were directed to small grants programs for faculty in the arts and humanities. We went out of our way to celebrate individual faculty accomplishments election to one of the national academies, appointments to endowed chairs. We raised some serious private money to support these areas.

Here is the principle I want to evoke: A great research university must maintain a balance, an equilibrium, between those areas that garner major external funding, and those that never will. Core areas of strength in key areas of the arts, humanities, and social sciences must be maintained. This requires a certain sophistication in the 
internal funding model, openness and transparency in the flow of funds, but above all, the strength and courage of top leadership to do what is necessary to support faculty research and creative activity in these areas.

Let me conclude, by simply summarizing the basic principles I have outlined in this paper, going back to my 1997 presentation.

- Lower the walls of the silos to facilitate inter-disciplinary work. Create inter- and multidisciplinary research clusters to address large problems.

- The greater the attempt, the greater the reward, and the greater risk for failure. Fear of failure often leads to the greatest failure of leadership - the failure to act.

- In developing institutional strategic objectives, one must always begin with an honest institutional assessment. I strongly believe in setting high goals - big hairy audacious goals, but those goals need to be grounded in reality.

- Facilities matter. We are, indeed, in an arms race. Good research facilities are a magnet for faculty and graduate students.

- Faculty have to be recruited in clusters in order to create major new initiatives, in addition to traditional departmental replacement hires. This requires an over-all architecture for strategic investment.

- Strong support from the state for research can leverage stronger federal and private support. We must never apologize for research, but rather celebrate it and find ways to connect it to people's lives.

- Public support for faculty compensation is vital. Faculty compensation is the most critical area of national competition. Everything hangs on the quality of the faculty.

- To be successful in big science, institutions need to think strategically, placing bets by allocating resources where there may be a big return. The major responsibility of top leadership is to set a vision and to be the cheer-leader-in-chief in articulating that vision to the university's many constituencies.

- A culture of entrepreneurship is a critical value. Success in economic development and job creation is the best argument for continued support for research. Avoid the traps. Don't overplay this hand. This must not be the only metric of success. The funding stream from licensing is not the goal.

- A great research university must maintain a balance, an equilibrium, between those areas that garner major external funding, and those that never will. It is a primary responsibility of top leadership to maintain areas of strength in key areas of the arts, humanities, and social sciences. This takes vision and courage. 


\section{References}

1. Mark Rogers. The Scientist. 1995

2. James Moeser, State of the University Address, September 4, 2002

3. James Moeser, State of the University Address, September 6, 2006

4. "UNC unveils innovative new licensing model to spur business spin-offs," UNC press release, December 10, 2009.

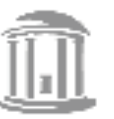

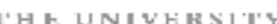

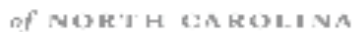

at CHAPEL H 1 L

The Task for Leadership

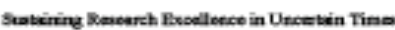

\section{The Task for Leadership}

- 2. The greater the attempt, the greater the reward. and the greater the risk for failure.

- It is this sobering realization, however, that often leads to the greatest failure of leadership - the failure to act.

- Institutions that coast are, by definition, on a downhill trajectory.

\section{ji]}

5. http://www.desimonegroup.chem.unc.edu/the-news/144techtransferpapermakestop10download-list; http://uncnews.unc.edu/content/view/31 $74 / 103 /$

The Task for Leadership

- 1. Lower the walls of the silos.

- "The instinutions that will succeod are those that can rearganize themseves to address scientific and educational questians in an interdisciplinary manner. The institurtions that will have ajfictily are the ones that kaop the same rigid stnucture that prevonts pollination among disciplines. "

- Mark Rogoer, The Seientirt, 1995.

Till $\mid x:-3, \cdots$

The Task for Leadership

- 3. In devolopieg institutioesal strategic objoctiver, one menst ahways bogin with an hocest institutioasl assessmeont.

- Sat high goals, but ground them in revlity.

I]

\section{The Task for Leadership}

- 4. Facilities matter.

- We are, indeed, in an arms race. Good research facilities are a magnet for faculty and graduate students.
The Task for Leadership

- 5. Recruit faculty in chasters.

- In order to initiate major new initiatives, faculty must be recruited in clusters, in addition to traditional departmental replacement hires. This requires an over-all architecture for strategic investment. 
The Task for Leadership

- 6. Strong support from the state can leverage stronger federal and private support.

- We must never apologize for research, but rather celebrate it and find ways to connect it to people's lives.

III
The Task for Leadership

- 7. Public support for faculty compensation is vital.

- This is the most critical area of national competition.

- Every thing hangs on the quality of the faculty.

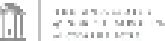

\section{The Task for Leadership}

- 8. To be successfil in big science, institutions need to think strategically. placing bets by allocating resources where there may be a big retum.

- The major responsibility of top leadership is to set a vision and to be the cheerleader-im-chief in articulating that vision to the umiversity's many coustituencies.

]
The Task for Leadership

- 9. A culture of entrepreneurship is a critical value. Success in economic development and job creation is the best argument for contimed support for research.

- Avoid the traps. Doa't overplay this hand. This must not become the only metric of success.

- The funding stream from licensing intellectual property is not the goal.

通|

The Task for Leadership

- 10. A great research university must maintain a balance, an equilibrium, between those areas that gamer major external funding and those that never will. It is the responsibility of top leadership to maintain excellence in the arts, humanities, and social sciences. This takes vision and courrage.

Tis 